\title{
A Bistatic Imaging Method for GEOSAR in the Strip Mode and UAVSAR in the Steering Beam Mode
}

\author{
W. Zhuo-qun (D), L. Ya-jun, S. Sheng, L. Shuang-shuang, X. Jin-guo, W. Jun-qiang, \\ and Z. Jian-hua
}

Shanghai Radio Equipment Research Institute, Shanghai 200090, China

Correspondence should be addressed to W. Zhuo-qun; wentingwangzhuoqun@126.com

Received 8 June 2018; Revised 30 July 2018; Accepted 5 September 2018; Published 31 October 2018

Academic Editor: Herve Aubert

Copyright (c) 2018 W. Zhuo-qun et al. This is an open access article distributed under the Creative Commons Attribution License, which permits unrestricted use, distribution, and reproduction in any medium, provided the original work is properly cited.

\begin{abstract}
The bistatic configuration with a geosynchronous orbital SAR (GEOSAR) transmitter and unmanned aerial vehicle SAR (UAVSAR) receiver can continuously image in any dangerous and interesting district. In this paper, the new imaging method in the case with the smaller orbital inclination of geosynchronous earth orbit and the steering beam working mode of UAVSAR was mainly studied and analyzed. GEOSAR can be approximately expressed as a static state, and only the receiver provides all the Doppler information. UAVSAR works in the steering beam modes, such as spotlight, sliding spotlight, and TOPS (Terrain Observation by Progressive Scan) mode. The azimuth bandwidth increased by the steering beam causes an aliasing situation in the azimuth frequency domain. To solve this problem, the proposed imaging method corrects the azimuth frequency aliasing using the scaling transform and the bulk azimuth compression. Compared with the traditional imaging method, the simulation validates perfectly the effectiveness of the bistatic imaging algorithm.
\end{abstract}

\section{Introduction}

Geosynchronous synthetic aperture radar (GEOSAR) is suitable for the continuous imaging in the specific partial region within the short revisit period of nearly $24 \mathrm{~h} \mathrm{[1-3].}$ However, the main difficulty for its hardware implementation is the large antenna and enough power of GEOSAR. The bistatic SAR configuration with a GEOSAR transmitter and unmanned aerial vehicle SAR receiver (GEO-UAV BiSAR) can reduce well the transmitted power and realize the imaging widely in any interesting and dangerous region [2].

For the short synthetic aperture time of this bistatic radar, GEOSAR on the small orbital inclination $\left(\leq 5^{\circ}\right)$ may be approximately considered a static situation, and only the receiver contributes to the all azimuth modulations $[4,5]$. The classical bistatic imaging algorithm cannot be employed to carry out this radar echo signal [6-9]. The imaging algorithm deals well with the data from the stationary transmitter and airborne receiver in the various working modes [10]. However, it is not considered that the azimuth bandwidth increased by antenna steering causes the aliasing in the azimuth frequency domain $[11,12]$. To solve this problem, one way is to increase the pulse repetition frequency (PRF). However, the high PRF leads to range ambiguity and limits the processing speed of data acquired by SAR. The other way using a subaperture approach $[13,14]$ is proposed, but the general section principle cannot be confirmed well. Hence, the scaling transform and the bulk azimuth compression are introduced to handle the echoes of GEO-UAV BiSAR in this paper.

This paper is organized as follows. In Section 2, the characteristic of GEO-UAV BiSAR configuration and the unified signal model are described. Section 3 presents the bistatic imaging method which eliminates the azimuth aliasing through the scaling transform and the bulk azimuth compression. Section 4 shows the simulations which indicate 
TABLE 1: The geometrical configuration of the GEO-UAV BiSAR. The time-frequency of received signals is plotted from three-point targets in near range (a), center range (b), and far range (c). $B_{i}$ represents the instantaneous signal bandwidth.

Mode \& description
Spotlight $\left(V_{R g}=0\right)$
Azimuth resolution: $\lambda R_{c R} / 2 L_{f R}$
Merits: this radar has the higher azimuth
resolution than the other three modes

Sliding spotlight $\left(0<V_{R g}<V_{R}\right)$

Azimuth resolution: $D / 2 \mu$

Merits: the receiver operated in a sliding spotlight mode achieves a tradeoff between the azimuth scene size and the azimuth resolution

Defects: as far as going studies in a large number of literatures are concerned, the less imaging method is appropriate [16]
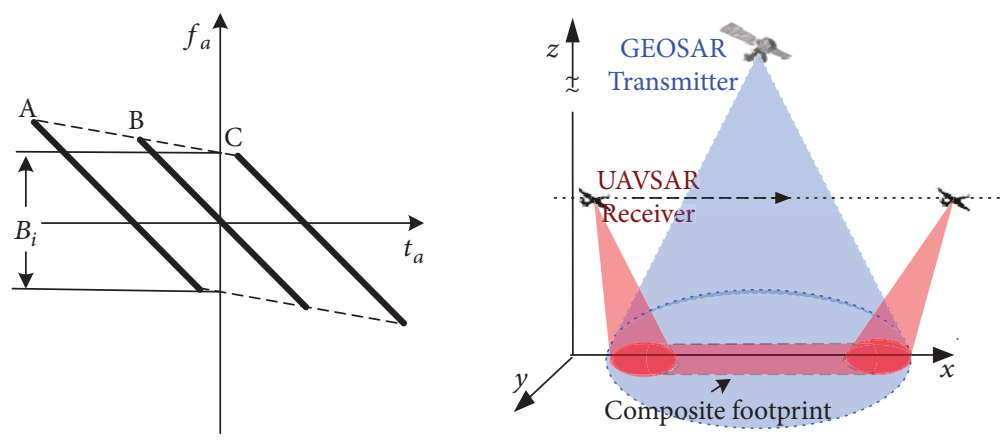

TOPS $\left(0<V_{R}<V_{R g}\right)$

Azimuth resolution: $D / 2 \mu$

Merits: the receiver in this type can switch the antenna to targets pertaining to different subswaths

Defects: this radar has the low azimuth resolution. A less imaging scheme can be applied [17]
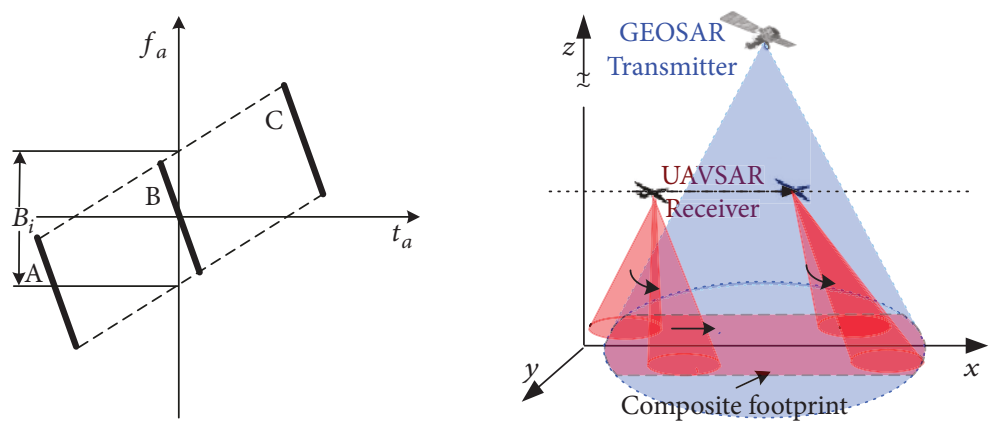

the correctness and the effectiveness of the proposed imaging algorithm.

\section{Uniform Signal Model of GEO-UAV BiSAR}

When the beam steering of the receiver is in the working mode, the time-frequency relationship and the bistatic geometrical configuration are shown in Table 1. In different working modes, the azimuth resolution ability is listed in the order TOPS $<$ sliding spotlight $<$ spotlight, whereas the surface coverage is listed in the reverse order. The particular bistatic geometric construction in the TOPS working mode is illustrated in Figure 1.

UAVSAR generates the virtual rotation point by antenna steering. The slant range between the receiver and the virtual rotation point is $R_{R \text { rot }}$. $V_{R g}$ shows the ground velocity of the receiver's antenna footprint. The beam velocity on the ground can be shown as $V_{R g}=\mu V_{R}$, where in the different working mode, $\mu_{\text {spot }}=0, \quad \mu_{\text {slid }}=\left(R_{R \text { rot }}-R_{0 R}\right) / R_{\text {Rrot }}$, and $\mu_{\text {tops }}=\left(R_{R \text { rot }}+R_{0 R}\right) / R_{R \text { rot }}$. The received signal from the target $P_{m}$ on the earth's surface after demodulation are expressed as

$$
\begin{aligned}
s s\left(t_{r}, t_{a}\right)= & \operatorname{rect}\left(\frac{\left(t_{a}-t_{a 0 R}\right) / \mu}{L_{f R} / V_{R}}\right) \\
& \cdot \operatorname{rect}\left(\frac{t_{r}-\left(\left(R_{T}\left(t_{a 0 R}, P_{m}\right)+R_{R}\left(t_{a}, P_{m}\right)\right) / C\right)}{T_{r}}\right) \\
& \cdot \exp \left(j \pi K_{r}\left(t_{r}-\frac{R_{T}\left(t_{a 0 R}, P_{m}\right)+R_{R}\left(t_{a}, P_{m}\right)}{C}\right)^{2}\right) \\
& \cdot \exp \left(-j \frac{2 \pi}{\lambda}\left(R_{T}\left(t_{a 0 R}, P_{m}\right)+R_{R}\left(t_{a}, P_{m}\right)\right)\right),
\end{aligned}
$$

where the first item $\operatorname{rect}(\cdot)$ represents the composite antenna pattern and shows the uniform illumination 


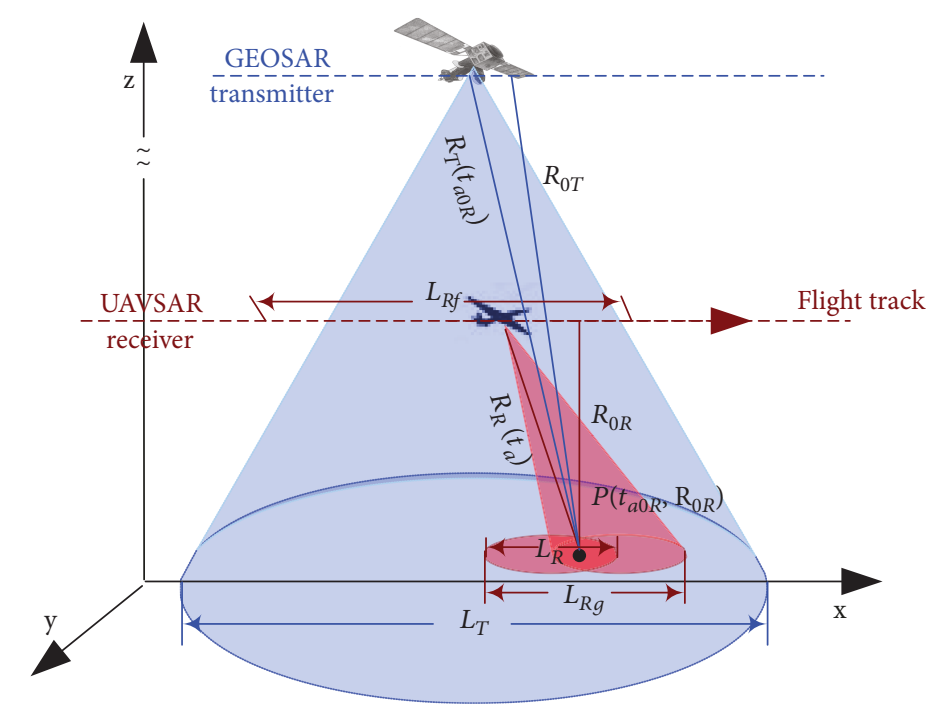

Figure 1: Geometrical configuration of GEO-UAV BiSAR (UAVSAR works in the TOPS mode).

over the ground in any working mode of the receiver. The second item $\operatorname{rect}(\cdot)$ represents the pulse envelope. $t_{r}$ and $t_{a}$ are the fast time and the slow time, respectively. $L_{f R}$ is the length of the receiver's flight path in the accumulated time. $t_{a 0 R}$ is the zero Doppler time of the receiver relative to the azimuth time origin $t_{a}=0 . V_{R}$ and $C$ represent the platform velocity of the receiver and the speed of radio, respectively. $\lambda$ and $F_{c}$ are the wavelength and the carrier frequency of the transmitted LFM, respectively. $T_{r}$ and $B_{r}$ show, respectively, the pulse duration and the bandwidth of transmitted LFM. $K_{r}$ denotes the FM rate.

$R_{T}\left(t_{a}, P_{m}\right)$ is the distance between the transmitter GEOSAR and the target $P_{m}$.

$$
R_{T}\left(t_{a}, P_{m}\right)=\sqrt{R_{0 T}^{2}+V_{T s} V_{T g}\left(t_{a}-t_{a 0 R}\right)^{2}},
$$

where $R_{0 T}$ denotes the slant range of the closest approach of the target to a virtual transmitter path which is assumed to be parallel with the receiver's trajectory.

When the orbital inclination is equal to $5^{\circ}$, the maximum of the approximated velocity is $22.07 \mathrm{~m} / \mathrm{s}$ in the orbital period. The variation of $R_{T}\left(t_{a}, P_{m}\right)$ calculated by (2) is less than $\lambda / 4$ [18]. Hence, $R_{T}\left(t_{a}, P_{m}\right)$ is simplified to $R_{0 T}$.

$R_{R}\left(t_{a}, P_{m}\right)$ represents the range from the receiver to the target.

$$
R_{R}\left(t_{a}, P_{m}\right)=\sqrt{R_{0 R}^{2}+V_{R}^{2}\left(t_{a}-t_{a 0 R}\right)^{2}},
$$

where $R_{0 R}$ is the slant range of the closest approach of the target to the receiver track.
Using the principle of stationary phase (POSP), the echoes are redescribed by Fourier transform in range as

$$
\begin{aligned}
S s\left(f_{r}, t_{a}\right)= & \operatorname{rect}\left(\frac{\left(t_{a}-t_{a 0 R}\right) / \mu}{L_{f R} / V_{R}}\right) \operatorname{rect}\left(\frac{f_{r}}{B_{r}}\right) \exp \left(-j \pi \frac{f_{r}^{2}}{K_{r}}\right) \\
& \cdot \exp \left(-j \frac{2 \pi\left(F_{c}+f_{r}\right)}{C}\left(R_{T}\left(t_{a 0 R}, P_{m}\right)+R_{R}\left(t_{a}, P_{m}\right)\right)\right) .
\end{aligned}
$$

It is important to note that the transmitter-related term in (4) does not depend on the azimuth slow time $t_{a}$ but only on the fixed position of the point target. And all the Doppler information comes from the receiver platform.

\section{Imaging Method for GEO-UAV BiSAR}

Beam steering increases the azimuth bandwidth during the data acquisition. Thus, the classical methods are not suitable to manage the signal processing of GEO-UAV BiSAR. In this section, we show the new imaging technology which consists of three parts including resolving aliasing, the range compression and the RFM processing, and the azimuth deramping operation. The basic operations of the new algorithm in Figure 2 are further illustrated in the following.

3.1. Block 1: Resolving Aliasing in Azimuth Frequency. The azimuth bandwidth increased with antenna steering. Thus, the aliasing problem in the azimuth frequency domain needs to be urgently solved. In the first step, a convolution between the echo and the reference function is executed. The reference function $s_{\text {ref }}\left(t_{a}\right)$ is given as

$$
s_{\mathrm{ref}}\left(t_{a}\right)=\exp \left(j \Omega \pi t_{a}^{2}\right), \quad \Omega=\frac{(1-\mu) V_{R}^{2}}{\lambda R_{0 R}} .
$$




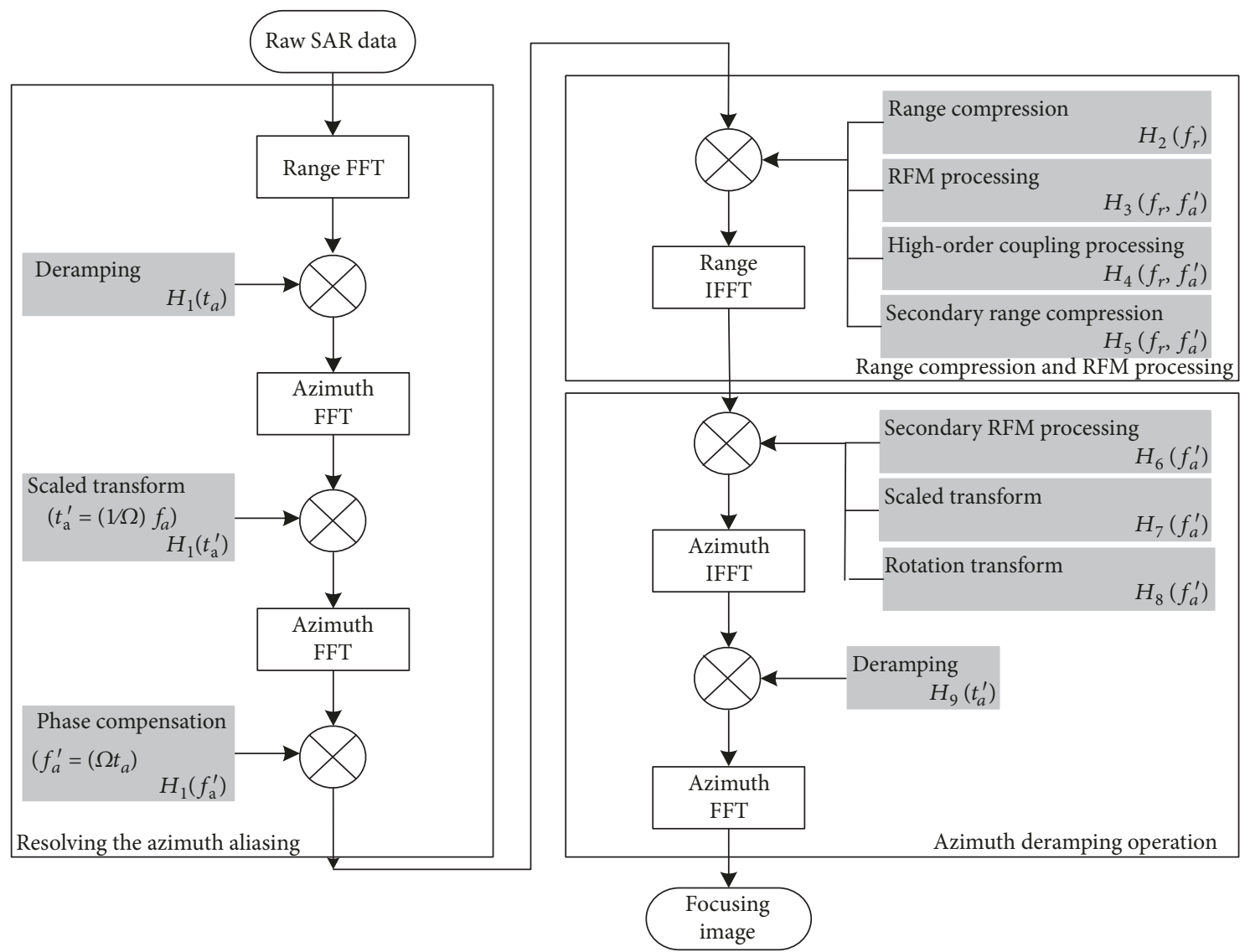

FIgURE 2: Diagram of the GEO-UAV BiSAR imaging method.

We simplify the calculation by the extension of the Bluenstein formula $[19,20]$.

$$
\begin{aligned}
S s^{\prime}\left(f_{r}, t_{a}^{\prime}\right)= & S s\left(f_{r}, t_{a}\right) \otimes s_{\text {ref }}\left(t_{a}\right) \\
= & \exp \left(j \pi \Omega t_{a}^{\prime} 2\right) \times \int S s\left(f_{r}, z\right) \exp \left(j \pi \Omega z^{2}\right) \\
& \cdot \exp \left(-j 2 \pi \Omega t_{a} z\right) d z .
\end{aligned}
$$

Equation (6) mainly contains two signal multiplications and a convolution. This course should be seen as a scaled inverse Fourier transform $\left(\mathrm{SCFT}^{-1}\right)$ from the original coordinate $t_{a}$ to the new one $t_{a}^{\prime}$. And the relation between $t_{a}^{\prime}$ and $f_{a}$ is $t_{a}^{\prime}=(1 / \Omega) f_{a}$. The signal $S s^{\prime}\left(f_{r}, t_{a}^{\prime}\right)$ in the twodimensional frequency domain can be redescribed as

$$
S S^{\prime}\left(f_{r}, f_{a}^{\prime}\right)=\operatorname{FFT}\left(S s^{\prime}\left(f_{r}, t_{a}^{\prime}\right)\right)=S S\left(f_{r}, f_{a}^{\prime}\right) S_{\text {ref }}\left(f_{a}^{\prime}\right)
$$

To obtain the echoes of the no-aliasing in the azimuth frequency domain, the signal $S S^{\prime}\left(f_{r}, f_{a}^{\prime}\right)$ is compensated by the function $H_{1}\left(f_{a}^{\prime}\right)$ in (8).

$$
S S_{1}^{\prime}\left(f_{r}, f_{a}^{\prime}\right)=S S^{\prime}\left(f_{r}, f_{a}^{\prime}\right) H_{1}\left(f_{a}^{\prime}\right)
$$

where $H_{1}\left(f_{a}^{\prime}\right)=\exp \left(j \pi(1 / \Omega) f_{a}^{\prime} 2\right)$.

The signal $S_{1}^{\prime}\left(f_{r}, f_{a}^{\prime}\right)$ without aliasing is obtained in (9), but the original PRF is increased through the above processing flow.

$$
\begin{aligned}
S S_{1}^{\prime}\left(f_{r}, f_{a}^{\prime}\right)= & \operatorname{rect}\left(\frac{f_{a}^{\prime}-f_{d c}}{B_{a}}\right) \operatorname{rect}\left(\frac{f_{r}}{B_{r}}\right) \exp \left(-j \pi \frac{f_{r}^{2}}{\gamma}\right) \\
& \cdot \exp \left(2 \pi f_{a}^{\prime} t_{a 0 R}\right) \exp \left(-j \frac{2 \pi\left(F_{c}+f_{r}\right)}{C} R_{0 T}\right) \\
& \cdot \exp \left(-j \frac{2 \pi R_{0 R}}{\lambda} \sqrt{\left(\frac{F_{c}+f_{r}}{F_{c}}\right)^{2}-\left(\frac{\lambda f_{a}^{\prime}}{V_{R}}\right)^{2}}\right),
\end{aligned}
$$

where $B_{r}$ and $B_{a}$ show, respectively, the range bandwidth and the Doppler bandwidth.

3.2. Block 2: Range Compression and RFM Processing. Range compression is performed for the signal $S_{1}^{\prime}\left(f_{r}, f_{a}^{\prime}\right)$, and the matched function $\mathrm{H}_{2}\left(f_{r}\right)$ is written as

$$
H_{2}\left(f_{r}\right)=\exp \left(j \pi \frac{f_{r}^{2}}{\gamma}\right) .
$$


For the existence of a space variant phase (it stands for azimuth compression, RCMC, and secondary range compression), we need to implement the RFM processing to focus the data at a reference slant range. And the matched filter is expressed as

$$
H_{3}\left(f_{r}, f_{a}^{\prime}\right)=\exp \left(j \frac{2 \pi R_{c R}}{\lambda} \sqrt{\left(\frac{F_{c}+f_{r}}{F_{c}}\right)^{2}-\left(\frac{\lambda f_{a}^{\prime}}{V_{R}}\right)^{2}}\right),
$$

where $R_{c R}$ is the slant range from the scene center to the receiver. RFM filtering correctly focuses the data at this reference slant range, partially compensating the phase of the target at other ranges. Through the steps $H_{1}: H_{3}$, the echoes can be described as

$$
\begin{aligned}
S S_{2}^{\prime}\left(f_{r}, f_{a}^{\prime}\right)= & \operatorname{rect}\left(\frac{f_{a}^{\prime}-f_{d c}}{B_{a}}\right) \operatorname{rect}\left(\frac{f_{r}}{B_{r}}\right) \exp \left(2 \pi f_{a}^{\prime} t_{a 0 R}\right) \\
& \cdot \exp \left(-j \frac{2 \pi\left(F_{c}+f_{r}\right)}{C} R_{c T}\right) \\
& \cdot \exp \left(-j \frac{2 \pi\left(R_{0 R}-R_{c R}\right)}{C} \sqrt{\left.\left(F_{c}+f_{r}\right)^{2}-\left(\frac{C f_{a}^{\prime}}{V_{R}}\right)^{2}\right) .}\right.
\end{aligned}
$$
Here, $f_{d c}$ is the Doppler centroid.
$\sqrt{\left(F_{c}+f_{r}\right)^{2}-\left(C f_{a}^{\prime} / V_{R}\right)^{2}}$ can be expanded by the Taylor
expansion in the four-order form.

$$
\begin{aligned}
& \sqrt{\left(F_{c}+f_{r}\right)^{2}-\left(\frac{C f_{a}^{\prime}}{V_{R}}\right)^{2}} \approx F_{c} \gamma\left(f_{a}^{\prime}\right)+\frac{f_{r}}{\gamma\left(f_{a}^{\prime}\right)}-\frac{1-\gamma^{2}\left(f_{a}^{\prime}\right)}{2 F_{c} \gamma^{3}\left(f_{a}^{\prime}\right)} \\
& \cdot f_{r}^{2}+\frac{1-\gamma^{2}\left(f_{a}^{\prime}\right)}{2 F_{c}^{2} \gamma^{5}\left(f_{a}^{\prime}\right)} \cdot f_{r}^{3},
\end{aligned}
$$

where $\gamma\left(f_{a}^{\prime}\right)=\sqrt{1-\left(\lambda f_{a}^{\prime} / V_{R}\right)^{2}}$.

On the right side of (13), the third term and the fourth term, respectively, stand for the high-order coupling of the two-dimensional frequency. These can be compensated fully by (14) and (15).

$$
H_{4}\left(f_{r}, f_{a}^{\prime}\right)=\exp \left(j \frac{\pi\left(R_{0 R}-R_{c R}\right)\left(1-\gamma^{2}\left(f_{a}^{\prime}\right)\right)}{C f_{c}^{2} \gamma^{5}\left(f_{a}^{\prime}\right)} \cdot f_{r}^{3}\right),
$$

$H_{5}\left(f_{r}, f_{a}^{\prime}\right)=\exp \left(-j \frac{\pi\left(R_{0 R}-R_{c R}\right)\left(1-\gamma^{2}\left(f_{a}^{\prime}\right)\right)}{C f_{c} \gamma^{3}\left(f_{a}^{\prime}\right)} \cdot f_{r}^{2}\right)$.

Then, the echoes can be written as

$$
\begin{aligned}
S S_{3}^{\prime}\left(f_{r}, f_{a}^{\prime}\right)= & \operatorname{rect}\left(\frac{f_{a}^{\prime}-f_{d c}}{B_{a}}\right) \operatorname{rect}\left(\frac{f_{r}}{B_{r}}\right) \exp \left(2 \pi f_{a}^{\prime} t_{a 0 R}\right) \\
& \cdot \exp \left(-j \frac{2 \pi\left(F_{c}+f_{r}\right)}{C} R_{0 T}\right) \\
& \cdot \exp \left(-j \frac{2 \pi\left(R_{0 R}-R_{c R}\right)}{C}\left(F_{c} \gamma\left(f_{a}^{\prime}\right)+\frac{f_{r}}{\gamma\left(f_{a}^{\prime}\right)}\right)\right) .
\end{aligned}
$$

3.3. Block 3: Azimuth Deramping Operation. Based on the aforementioned imaging processing, the partial echoes are compensated at the no-reference slant range. $S_{3}^{\prime}\left(f_{r}, f_{a}^{\prime}\right)$ without azimuth frequency aliasing is gained. However, there still exists the aliasing in the azimuth time domain. Therefore, Block 3 mainly consisted of three components that include secondary RFM, the scaled transform, and the deramping operation.

In the large coverage (especially TOPS mode), RFM processing can only make the most part of echoes at the reference slant range, and the rest of the echoes are compressed at the other range. Hence, in order to check all the echoes in the reference slant range, we further carry out the secondary RFM processing implemented by dividing the data into the small range blocks. The secondary RFM function is expressed as

$$
H_{6}\left(f_{r}, f_{a}\right)=\exp \left(j \frac{2 \pi\left(R_{m}-R_{c R}\right)}{C}\left(F_{c} \gamma\left(f_{a}^{\prime}\right)+\frac{f_{r}}{\gamma\left(f_{a}^{\prime}\right)}\right)\right),
$$

where the subscript $m$ stands for the index of the range blocks across the whole swath. And $R_{m}$ is referred to as the reference slant range of the $m$ th block (the midswath range in the block). Due to RFM errors, the azimuth broadening is less than $2 \%$, and the focusing imaging results are obtained. The signal in the range time and azimuth frequency domain is written as

$$
\begin{aligned}
S S_{4}^{\prime}\left(t_{r}, f_{a}^{\prime}\right)= & \operatorname{rect}\left(\frac{f_{a}^{\prime}-f_{d c}}{B_{a}}\right) \exp \left(2 \pi f_{a}^{\prime} t_{a 0 R}\right) w_{r} \\
& \cdot\left(t_{r}-\frac{\left(R_{0 T}+\left(R_{0 R}-R_{m}\right)\right)}{C}\right) \\
& \cdot \exp \left(-j \frac{2 \pi}{\lambda}\left(R_{0 T}+\left(R_{0 R}-R_{m}\right) \gamma\left(f_{a}^{\prime}\right)\right)\right) .
\end{aligned}
$$


Then, the scaled transform is used to obtain the signal of no-aliasing in azimuth, including the rotation processing $H_{7}\left(f_{a}^{\prime}\right)$ and the rotation transform $H_{8}\left(f_{a}^{\prime}\right)$.

$$
\begin{aligned}
& H_{7}\left(f_{a}^{\prime}\right)=\exp \left(j \frac{2 \pi}{\lambda}\left(R_{0 R}-R_{m}\right) \gamma\left(f_{a}^{\prime}\right)\right) \\
& H_{8}\left(f_{a}^{\prime}\right)=\exp \left(j \pi \frac{1-\mu}{\Omega} f_{a}^{\prime} 2\right) \exp \left(-j \pi \frac{1}{\Omega} f_{a}^{\prime} 2\right) .
\end{aligned}
$$

After azimuth IFFT, we obtain the signal $s s_{5}^{\prime}\left(t_{r}, t_{a}^{\prime}\right)$ without the aliasing in the two-dimensional time domain.

$$
\begin{aligned}
s s_{5}^{\prime}\left(t_{r}, t_{a}^{\prime}\right)= & \operatorname{rect}\left(\frac{t_{a}^{\prime}-\kappa t_{a 0 R}}{L_{f R} / V_{R}}\right) \exp \left(-j \frac{2 \pi}{\lambda} R_{0 T}\right) w_{r} \\
& \cdot\left(t_{r}-\frac{\left(R_{0 T}+\left(R_{0 R}-R_{m}\right)\right)}{C}\right) \\
& \cdot \exp \left(j \pi \frac{\Omega V_{R}}{2 V_{R}-V_{R g}}\left(t_{a}^{\prime}-t_{a 0 R}\right)^{2}\right) .
\end{aligned}
$$

Then, the deramping processing is implemented in this step, and the compensated function is defined as

$$
H_{9}\left(t_{a}^{\prime}\right)=\exp \left(-j \pi \frac{\Omega}{\mu} t_{a}^{\prime} 2\right)
$$

Finally, after the azimuth Fourier transform, the echoes can be redescribed as

$$
\begin{aligned}
s s_{6}^{\prime}\left(t_{r}, t_{a}^{\prime}\right)= & w_{r}\left(t_{r}-\frac{R_{0 T}+\left(R_{c R}-R_{m}\right)}{C}\right) w_{a}\left(t_{a}^{\prime}-t_{a 0 R}\right) \\
& \cdot \exp \left(-j \frac{2 \pi}{\lambda} R_{0 T}\right) .
\end{aligned}
$$

\section{Simulation Analysis}

To verify the correctness of the proposed imaging method, we use the data collection geometry illustrated in Figure 3 to perform the simulation.

4.1. Imaging Simulation for the Single-Point Target. We use the proposed method and the old imaging method [10] to handle the echoes from the point target P5 in the spotlight mode of the receiver, respectively.

The simulation parameters are listed in Table 2. GEOSAR works at X-band. Under the condition of the LFM bandwidth $=80 \mathrm{MHz}$, the theoretical range resolution attains $1.86 \mathrm{~m}$. PRF is set to $120 \%$ of the instantaneous bandwidth, i.e., $\mathrm{PRF}=1555 \mathrm{~Hz}$. And UAV works with the velocity

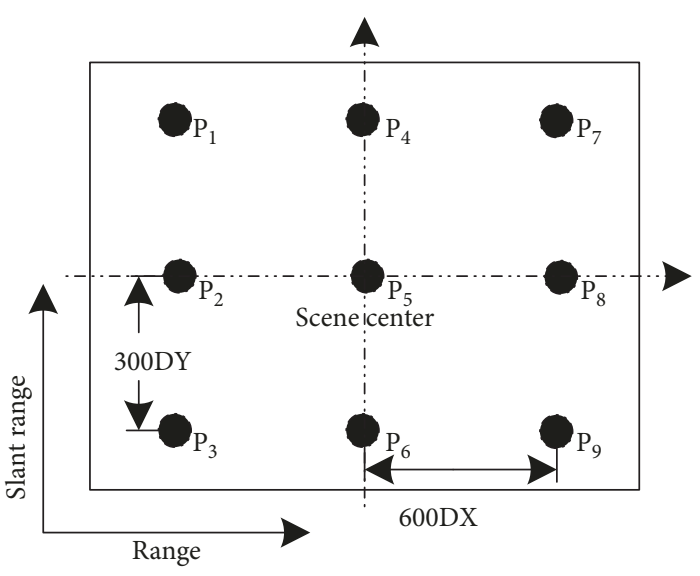

Figure 3: The composite scene with 9-point targets. Here, DX and DY represent the azimuth and the range resolution, respectively.

TABLE 2: Simulation parameters.

\begin{tabular}{lc}
\hline Parameter & Value \\
\hline GEOSAR altitude & $36,000 \mathrm{~km}$ \\
Wavelength & $0.03 \mathrm{~m}$ (X-band) \\
Bandwidth & $80 \mathrm{MHz}$ \\
Pulse duration & $20 \mu \mathrm{s}$ \\
UAVSAR altitude & $8000 \mathrm{~m}$ \\
Antenna size of UAVSAR & $2 \mathrm{~m}$ \\
UAVSAR velocity & $200 \mathrm{~m} / \mathrm{s}$ \\
$\begin{array}{l}\text { Azimuth aperture angle in the case } \\
\text { of the receiver's spotlight mode }\end{array}$ & $12^{\circ}$ \\
$\begin{array}{l}\text { The beam velocity of UAVSAR in } \\
\text { the sliding spotlight mode } \\
\text { The beam velocity of UAVSAR in } \\
\text { the TOPS mode }\end{array}$ & $140 \mathrm{~m} / \mathrm{s}$ \\
\end{tabular}

$200 \mathrm{~m} / \mathrm{s}$ in the spotlight mode. We, respectively, use the proposed method and the method referenced in [10] to handle the echoes from the point target P5 located on the position coordinate $(0 \mathrm{~m}, 0 \mathrm{~m}$, and $0 \mathrm{~m})$. In the receiver's spotlight mode, the azimuth resolution reaches $0.15 \mathrm{~m}$.

The echo signal of the single-point target is managed, respectively, using the imaging method referenced in [10] and the proposed imaging algorithm. The imaging results are shown in Figures 4 and 5. Using the imaging algorithm referenced in [10], the aliasing situation in the azimuth frequency spectrum is more obvious. The imaging results show the three-point targets in the scene. However, in fact, all echoes only come from a real point target P5, and the two points on the edge of Figure 4(b) are illusory. Hence, the real location of the point target cannot be clearly known by this method.

Then, using the proposed imaging algorithm in this paper, the two-dimensional frequency spectrum with no aliasing is obtained. The results indicate a clear point target in the center of the scene. It is the reason why the new imaging method perfectly solves the azimuth frequency 


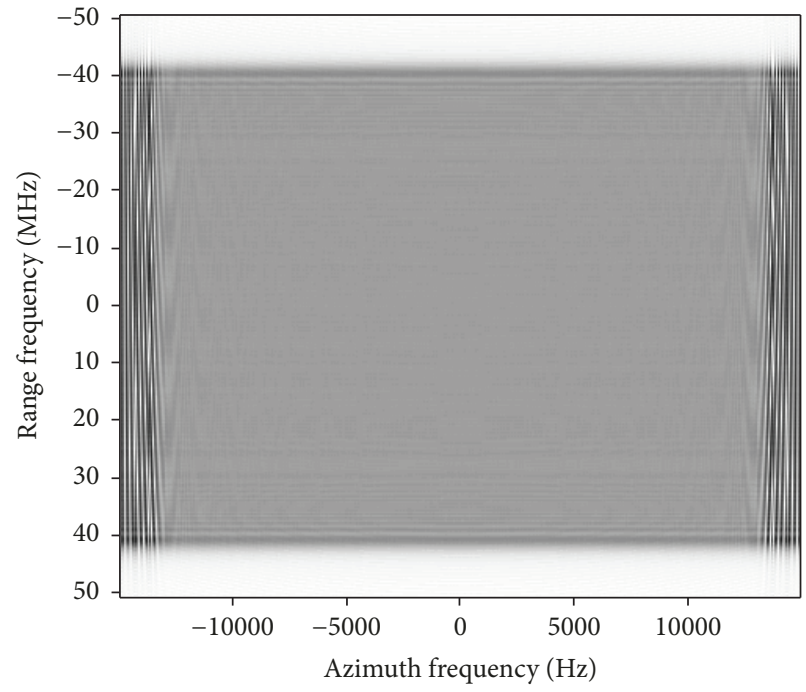

(a) Two-dimensional frequency spectrum of the point target

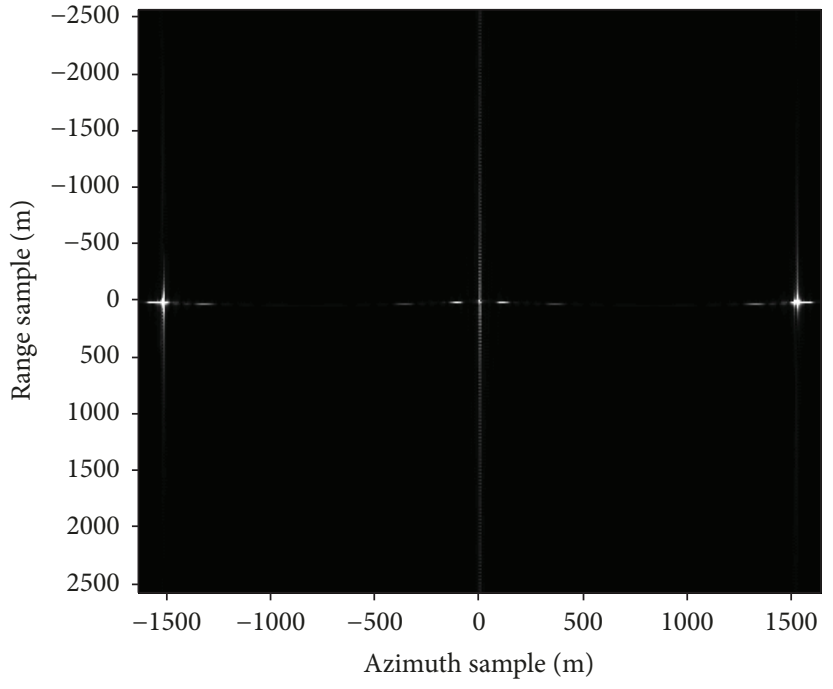

(b) Imaging results of the point target

Figure 4: Imaging results by the traditional method in literature [10].

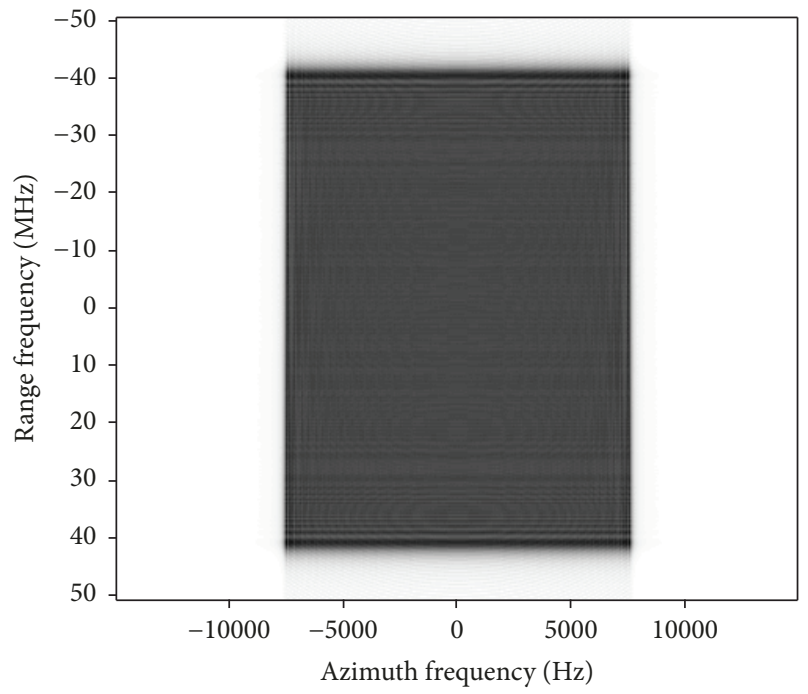

(a) Two-dimensional frequency spectrum of the point target

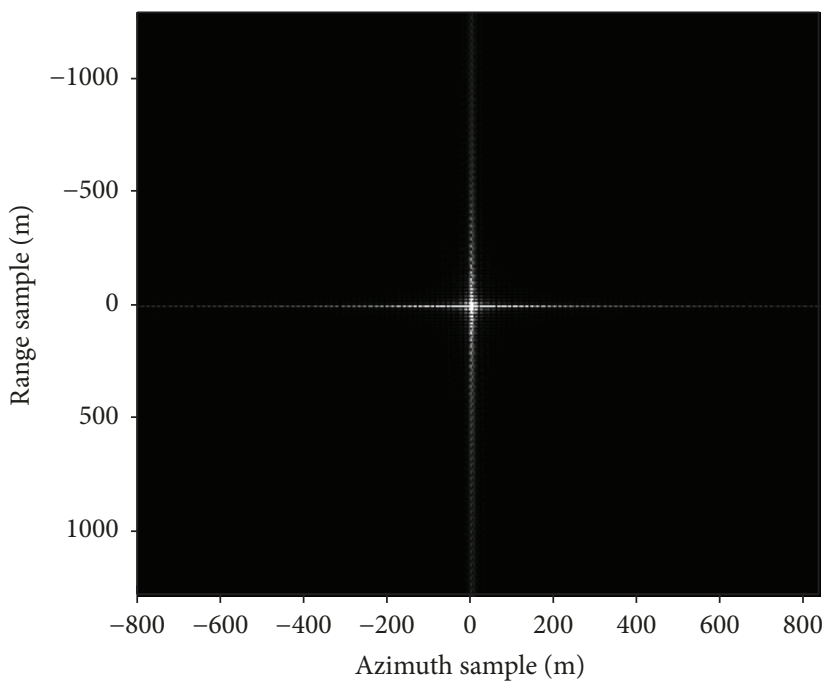

(b) Imaging results of the point target

FIGURE 5: Imaging result by the proposed imaging method.

aliasing for antenna steering. Compared with the imaging algorithm referenced in [10], the proposed approach reduces the instantaneous azimuth bandwidth that increased with antenna steering and avoids the azimuth aliasing issue well. To further confirm the effectiveness of the new method quantitatively, imaging results of the point target will be evaluated by three indexes including the peak sidelobe ratio (PSLR), the integration sidelobe ratio (ISLR), and the impulse response width (IRW). In the range direction, PSLR $=-13.25 \mathrm{~dB}$, ISLR $=-9.45 \mathrm{~dB}$, and $\mathrm{IRW}=1.95 \mathrm{~m}$, and in azimuth, PSLR $=-13.27 \mathrm{~dB}$, ISLR $=-9.48 \mathrm{~dB}$, and IRW $=0.15 \mathrm{~m}$. It can be clearly found that the imaging results are close to the theoretical values. For the receiver's various working mode, the radar in the spotlight mode has the larger increments of the azimuth bandwidth than that in the other mode. Hence, this new method is appropriate for GEOUAV BiSAR in the receiver's various working mode.

4.2. Imaging Simulation for the Multipoint Targets. To present the validity of the proposed imaging method, we perform the imaging simulation of the multipoint targets in the various modes of the receiver. PRF is $20 \%$ greater than the instantaneous azimuth bandwidth in the simulation, and $\mathrm{PRF}_{\text {spot }}=1555 \mathrm{~Hz}, \mathrm{PRF}_{\text {sliding }}=171 \mathrm{~Hz}$, and $\mathrm{PRF}_{\text {strip }}=$ $88 \mathrm{~Hz}$. Based on the simulated parameters listed in Table 2, we obtain the ideal range resolution to $1.87 \mathrm{~m}$. In UAVSAR's various working modes, the theoretical azimuth resolution follows $\mathrm{DX}_{\text {spot }}=0.15 \mathrm{~m}, \mathrm{DX}_{\text {sliding }}=1.40 \mathrm{~m}$, and $\mathrm{DX}_{\text {TOPS }}=$ $2.70 \mathrm{~m}$. 


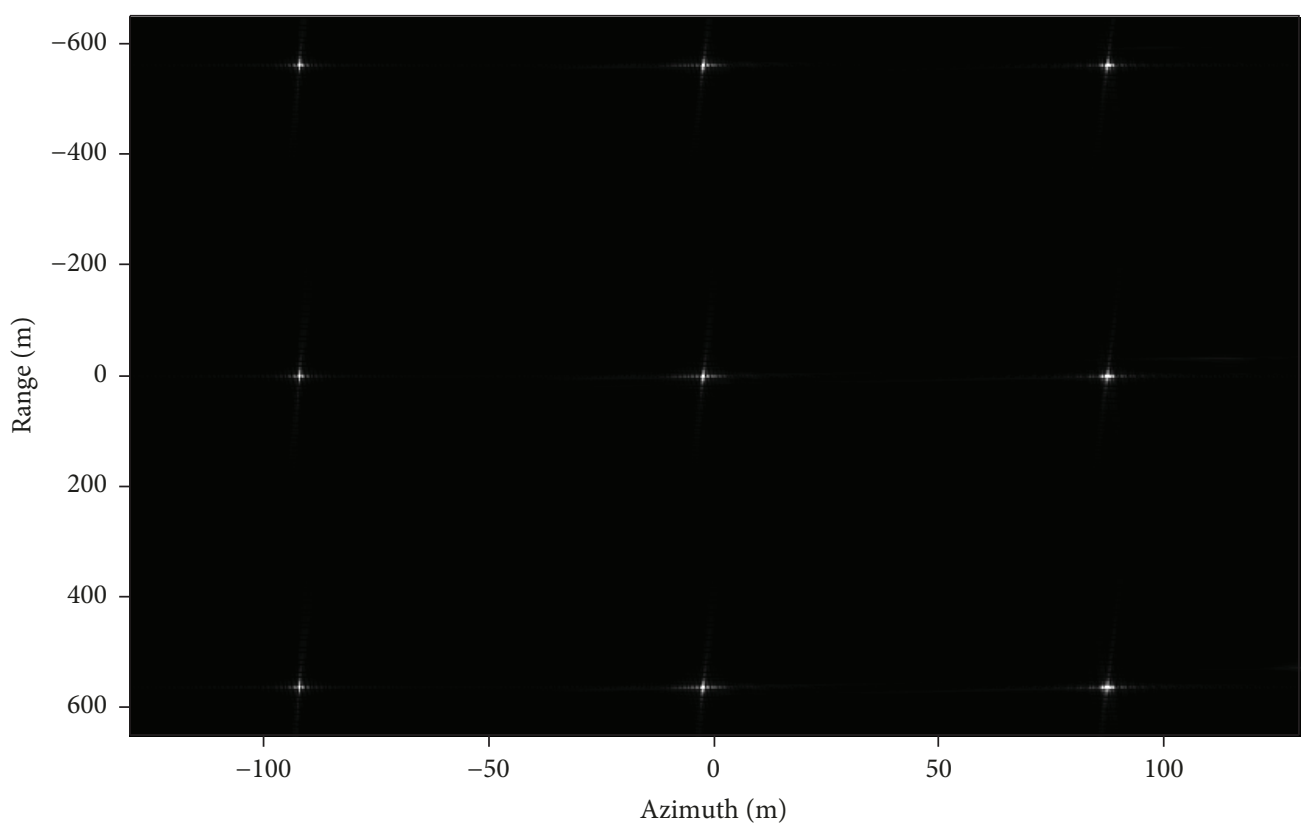

(a) Multipoint imaging results

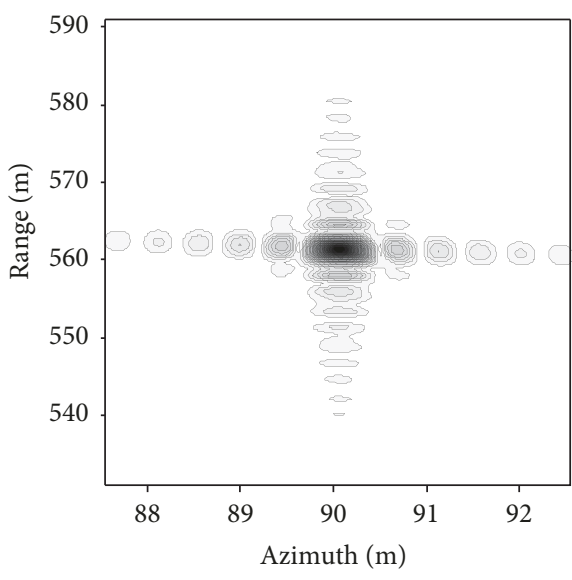

(b) Imaging result of P3

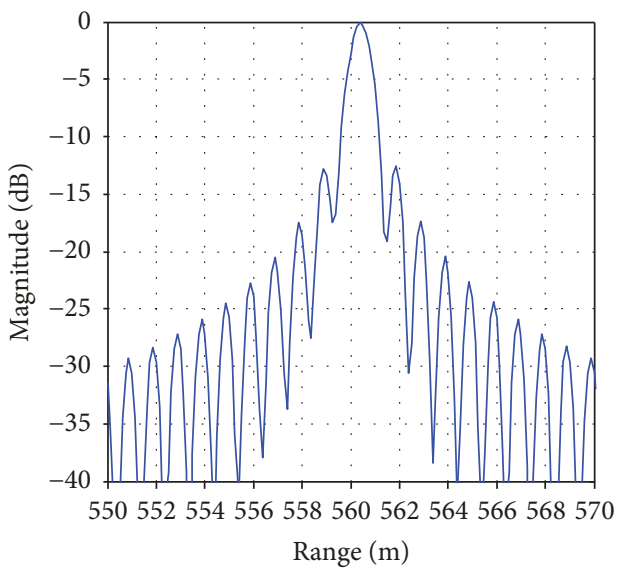

(c) Range response profile of P3

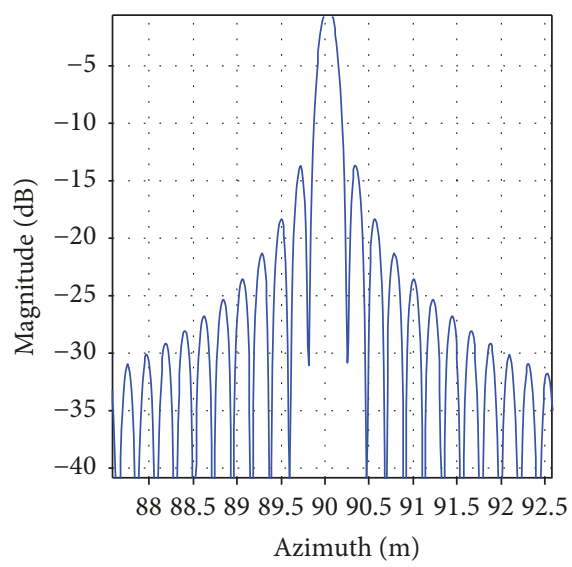

(d) Azimuth response profile of P3

FIGURE 6: Imaging results in the spotlight mode of the receiver.

The received signals from the multipoint targets are operated by the proposed imaging algorithm. Figures 6-8(a) mainly show the imaging results of 9-point targets in the steering antenna working mode. And Figures 6, 7, and $8(\mathrm{~b})-8(\mathrm{~d})$, respectively, describe the two-dimensional profiles of the single-point P3. Subsequently, the imaging 


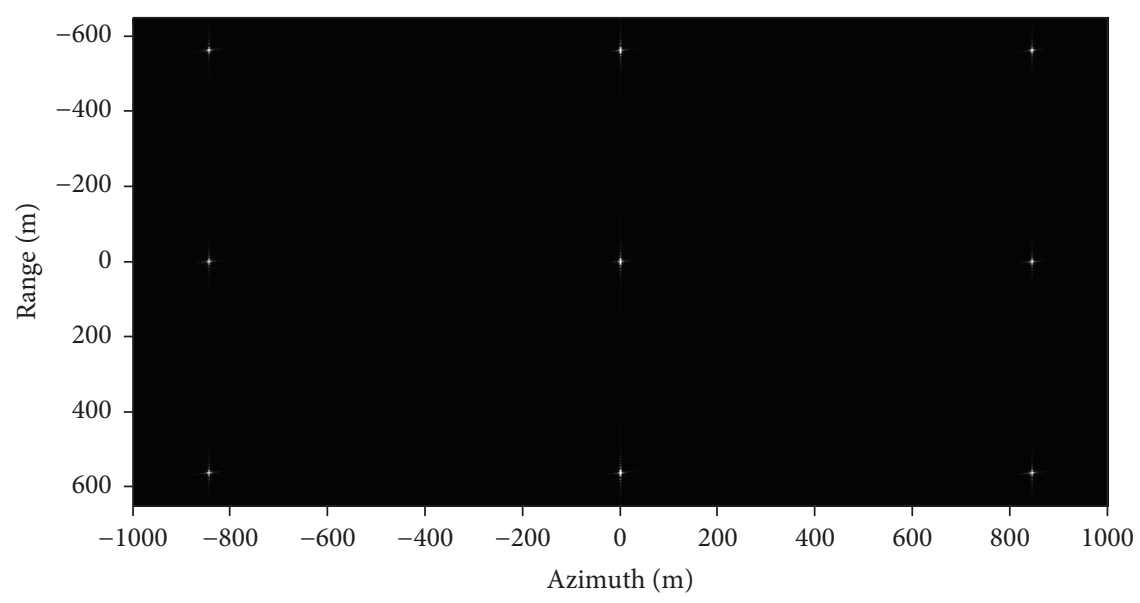

(a) Multipoint imaging results

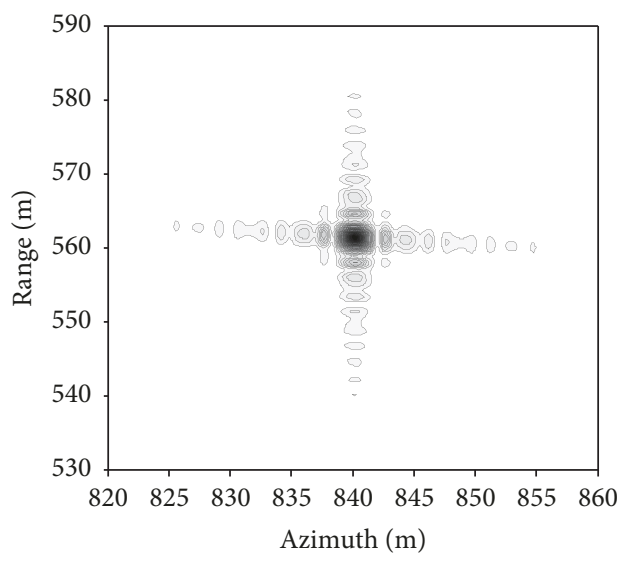

(b) Imaging result of $\mathrm{P} 3$

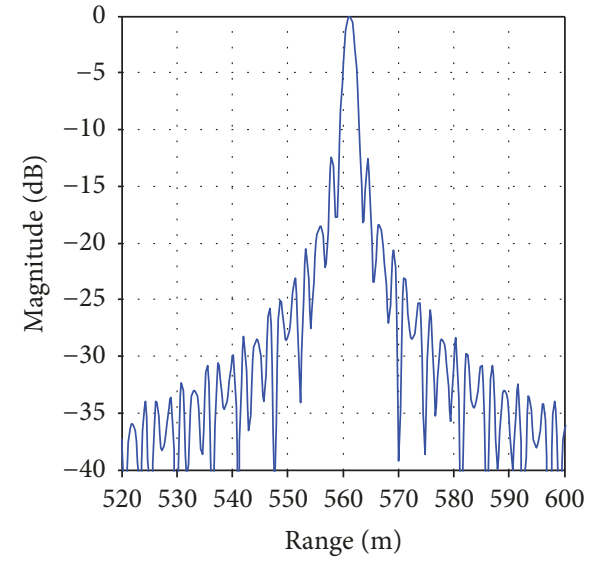

(c) Range response profile of P3

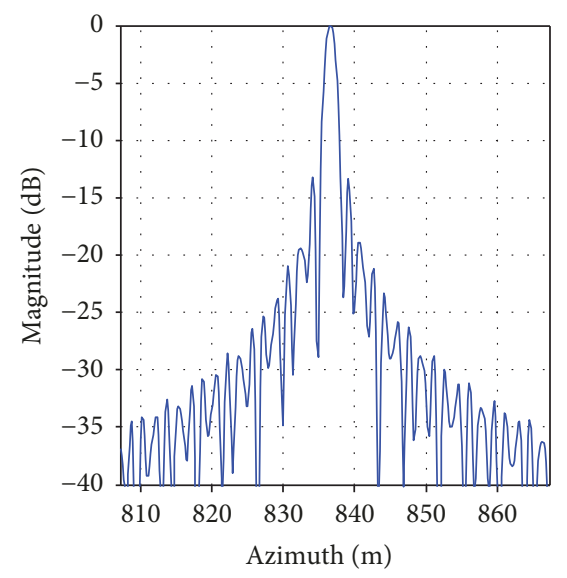

(d) Azimuth response profile of P3

FIgURE 7: Imaging results in the sliding spotlight mode of the receiver.

qualities of the partial point targets, i.e., PSLR, ISLR, and IRW, are revealed in Table 3. When UAVSAR works in the spotlight mode, the targets of $\mathrm{P} 3$ and $\mathrm{P} 7$ had a maximum expansion of $4.28 \%$ in range and $6.67 \%$ in azimuth. In the sliding spotlight working mode of the receiver, P5, located at the screen center, has the good imaging quality with $1.87 \mathrm{~m}$ in range and $1.40 \mathrm{~m}$ in azimuth. And in the receiver's
TOPS mode, P5 possesses an ideal range impulse response and the azimuth impulse response expands to $2.96 \%$. Then, it is seen that, in the various working modes of the receiver, the reference target and its neighbors are well focused in the imaging results of the scene. The experiment demonstrates that the proposed algorithm can be perfectly applied to processing the GEO-UAV BiSAR echoes. 


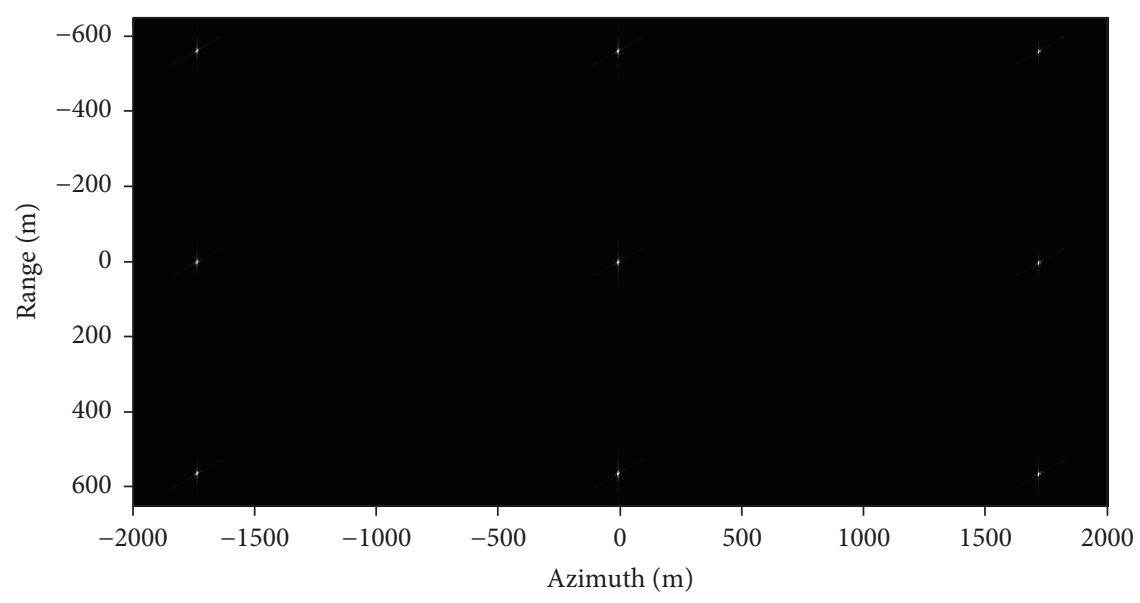

(a) Multipoint imaging results

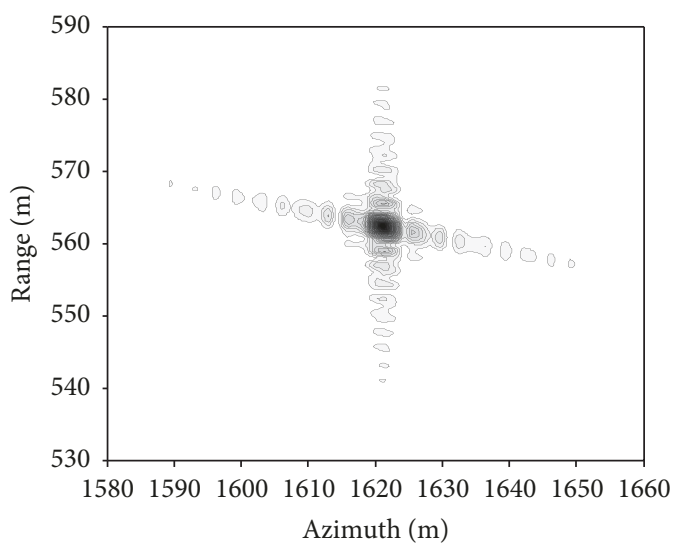

(b) Imaging result of P3

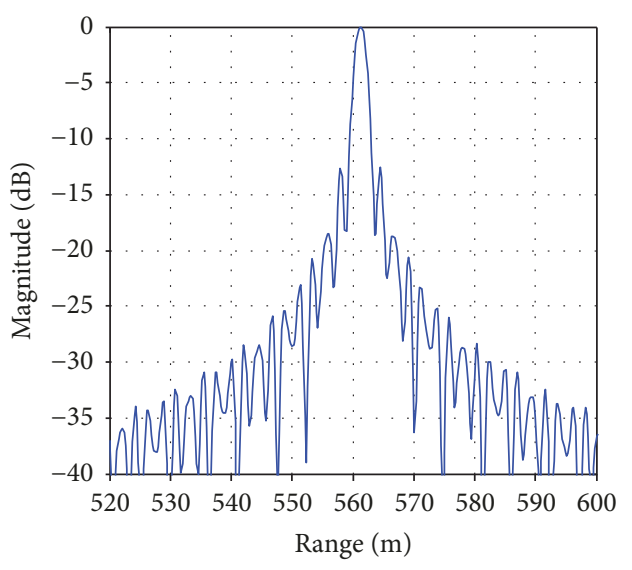

(c) Range response profile of P3

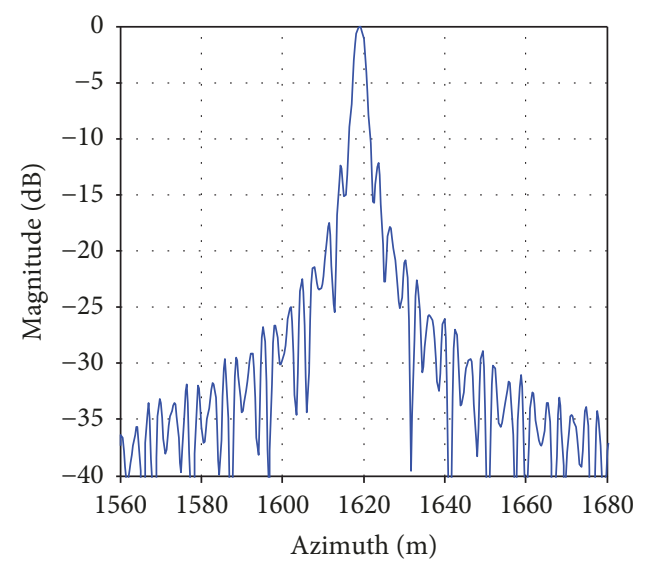

(d) Azimuth response profile of P3

FIGURE 8: Imaging results in the TOPS mode of the receiver.

\section{Conclusions}

We have introduced a uniform bistatic imaging algorithm for processing the echoes from the GEO-UAV BiSAR in the antenna steering working mode of the receiver (i.e., spotlight, sliding spotlight, and TOPS). The transmitter with GEOSAR on the small inclination is confirmed as a quiescent state, and UAVSAR offers all Doppler information. That Doppler bandwidth increased by antenna steering generates the aliasing problem in the azimuth frequency domain making the classical bistatic imaging methods inappropriate for this radar. The proposed imaging algorithm mainly includes the scale transform and bulk azimuth compression, the range compression and the RFM processing, the scaling transform and deramping approaches. In comparison with the imaging method referenced in [10], the proposed algorithm 
TABLE 3: Imaging qualities of the multipoint targets (P1, P5, and P9).

\begin{tabular}{|c|c|c|c|c|c|c|c|}
\hline \multirow{2}{*}{ Receiver mode } & \multirow{2}{*}{ Location of point targets } & \multicolumn{3}{|c|}{ Range } & \multicolumn{3}{|c|}{ Azimuth } \\
\hline & & PSLR (dB) & ISLR (dB) & Resolution (m) & $\operatorname{PSLR}(\mathrm{dB})$ & ISLR (dB) & Resolution (m) \\
\hline \multirow{3}{*}{ Spotlight } & P3 & -13.27 & -9.26 & 1.95 & -13.79 & -9.38 & 0.16 \\
\hline & P5 & -13.25 & -9.45 & 1.95 & -13.27 & -9.52 & 0.15 \\
\hline & P7 & -13.32 & -9.47 & 1.95 & -13.76 & -9.54 & 0.16 \\
\hline \multirow{3}{*}{ Sliding spotlight } & P3 & -13.15 & -9.52 & 1.87 & -13.54 & -9.45 & 1.54 \\
\hline & P5 & -13.23 & -9.51 & 1.87 & -13.26 & -9.63 & 1.40 \\
\hline & P7 & -12.89 & -9.33 & 1.93 & -12.85 & -9.42 & 1.55 \\
\hline \multirow{3}{*}{ TOPS } & P3 & -13.22 & -9.64 & 1.87 & -13.34 & -9.45 & 2.81 \\
\hline & P5 & -13.01 & -9.26 & 1.87 & -13.21 & -9.43 & 2.78 \\
\hline & P7 & -12.84 & -9.62 & 1.87 & -13.10 & -9.75 & 2.80 \\
\hline
\end{tabular}

verifies its correctness and effectiveness via simulations. It solves the aliasing frequency problem and well focuses the bistatic data on the real position of the point targets in the large scene.

In our future work, we will further study the bistatic imaging method for GEOSAR on the large orbital inclination.

\section{Data Availability}

All data included in this study are available from the corresponding author upon request.

\section{Conflicts of Interest}

The authors declare no competing financial interest.

\section{Acknowledgments}

We would like to express our sincere thanks to the National Natural Science Foundation Project (grant no. 61701309) and the Shanghai Natural Science Foundation (grant no. 17ZR1428800) and to the members of the Shanghai Radio Equipment Research Institute for the technical support.

\section{References}

[1] K. Tomiyasu, "Synthetic aperture radar in geosynchronous orbit," in 1978 Antennas and Propagation Society International Symposium, pp. 42-45, Washington, DC, USA, March 1978.

[2] J. Palmer, S. Palumbo, A. Summers, D. Merrett, and S. Howard, "DSTO's experimental geosynchronous satellite based PBR," in 2009 International Radar Conference "Surveillance for a Safer World" (RADAR 2009), pp. 1-6, Bordeaux, France, October 2009.

[3] Y. Jiang and Z. Wang, "Analysis for resolution of bistatic SAR configuration with geosynchronous transmitter and UAV receiver," International Journal of Antennas and Propagation, vol. 2013, Article ID 237463, 10 pages, 2013.

[4] S. R. Stevens and J. A. Jackson, "Emitter selection criteria for passive multistatic synthetic aperture radar imaging," IET Radar, Sonar \& Navigation, vol. 8, no. 9, pp. 1267-1279, 2014.

[5] I. C. Sikaneta, "A hybrid SAR processing method for data collected using a stationary bistatic receiver," in 7th European Conference on Synthetic Aperture Radar, pp. 1-4, Friedrichshafen, Germany, June 2008.

[6] R. Wang, O. Loffeld, Y. L. Neo, and H. Nies, "Extending Loffeld's bistatic formula for the general bistatic SAR," IET Radar, Sonare Navigation, vol. 4, no. 1, pp. 74-84, 2010.

[7] Y. Liu, Y. K. Deng, R. Wang, O. Loffeld, and X. Wang, "Model and signal processing of bistatic frequency modulated continuous wave synthetic aperture radar," IET Radar, Sonar \& Navigation, vol. 6, no. 6, pp. 472-482, 2012.

[8] J. Shaffer, B. A. Cooper, K. W. Hom, R. C. Baucke, and N. A. Talcott, "A review of bistatic K-space imaging for electromagnetic prediction codes for scattering and antennas," IEEE Antennas and Propagation Magazine, vol. 39, no. 5, pp. 21-29, 1997.

[9] A. S. Goh, M. Preiss, N. J. S. Stacy, and D. A. Gray, "Bistatic SAR experiment with the ingara imaging radar: preliminary results," in 7th European Conference on Synthetic Aperture Radar, pp. 89-105, Friedrichshafen, Germany, June 2011.

[10] R. Wang, O. Loffeld, Y. L. Neo et al., "Focusing bistatic SAR data in airborne/stationary configuration," IEEE Transactions on Geoscience and Remote Sensing, vol. 48, no. 1, pp. 452465, 2010.

[11] W. G. Carrara, R. S. Goodman, and M. A. Ricoy, "New algorithms for widefield SAR image formation," in Proceedings of the 2004 IEEE Radar Conference (IEEE Cat. No.04CH37509), pp. 38-43, Philadelphia, PA, USA, April 2004.

[12] Y. Wu, G. C. Sun, X. G. Xia, M. Xing, J. Yang, and Z. Bao, “An azimuth frequency non-linear chirp scaling (FNCS) algorithm for TOPS SAR imaging with high squint angle," IEEE Journal of Selected Topics in Applied Earth Observations and Remote Sensing, vol. 7, no. 1, pp. 213-221, 2013.

[13] P. Prats, R. Scheiber, J. Mittermayer, A. Meta, and A. Moreira, "Processing of sliding spotlight and TOPS SAR data using baseband azimuth scaling," IEEE Transactions on Geoscience and Remote Sensing, vol. 48, no. 2, pp. 770-780, 2010.

[14] F. He, Q. Chen, Z. Dong, and Z. Sun, "Processing of ultrahighresolution spaceborne sliding spotlight SAR data on curved orbit," IEEE Transactions on Aerospace and Electronic Systems, vol. 49, no. 2, pp. 819-839, 2013.

[15] Y. Mo, Y. K. Deng, Y. H. Luo, B. J. Zhao, and H. Yan, "New development of two-step processing approach for spotlight SAR focusing in presence of squint," Progress In Electromagnetics Research, vol. 139, no. 139, pp. 317-334, 2013.

[16] M. Rodriguez-Cassola, P. Prats-Iraola, F. De-Zan, and R. Scheiber, "Doppler-related distortions in TOPS SAR 
images," IEEE Transactions on Geoscience and Remote Sensing, vol. 53, no. 1, pp. 25-35, 2015.

[17] J. Mittermayer, R. Lord, and D. Borner, "Sliding spotlight SAR processing for Terra SAR-X using a new formulation of the extended chirp scaling algorithm," in IGARSS 2003. 2003 IEEE International Geoscience and Remote Sensing Symposium. Proceedings (IEEE Cat. No.03CH37477), pp. 1462-1464, Toulouse, France, July 2003.

[18] L. L. Kou, M. Xiang, X. Wang, and M. Zhu, "Tropospheric effects on L-band geosynchronous circular SAR imaging," IET Radar, Sonar \& Navigation, vol. 7, no. 6, pp. 693-701, 2013.

[19] G. Sun, M. Xing, Y. Wang, and Y. Wu, "Sliding spotlight and TOPS SAR data processing without subaperture," IEEE Geoscience and Remote Sensing Letters, vol. 8, no. 6, pp. 1036-1040, 2011.

[20] I. G. Cumming and F. H. Wong, Digital Processing of Synthetic Aperture Radar Data Algorithms and Implementation, Artech House, Norwood, MA, USA, 2005. 


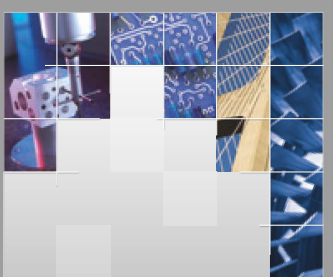

\section{Enfincering}
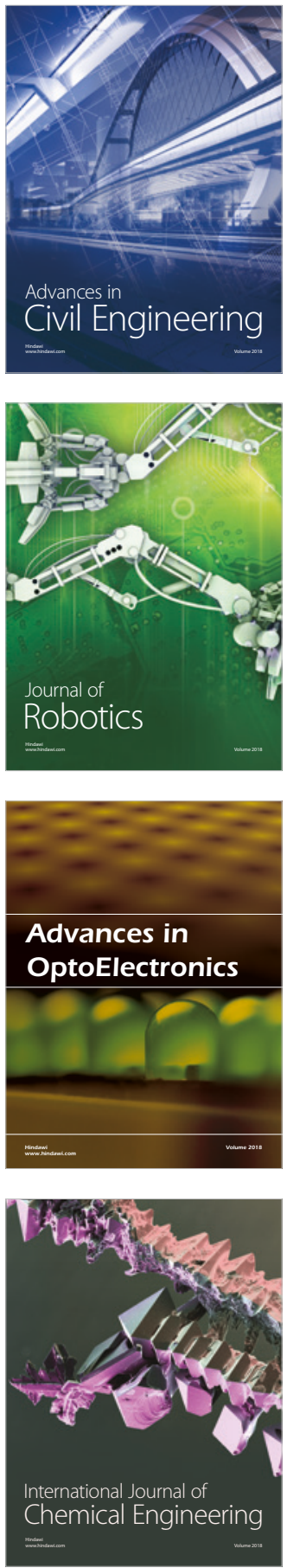

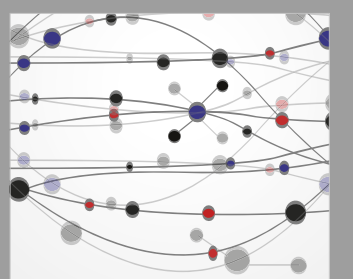

\section{Rotating \\ Machinery}

The Scientific World Journal

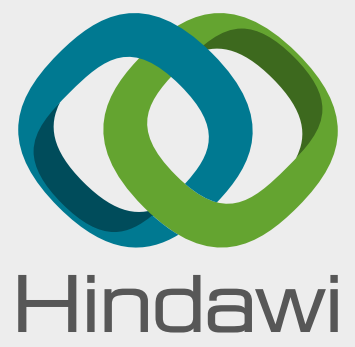

Submit your manuscripts at

www.hindawi.com
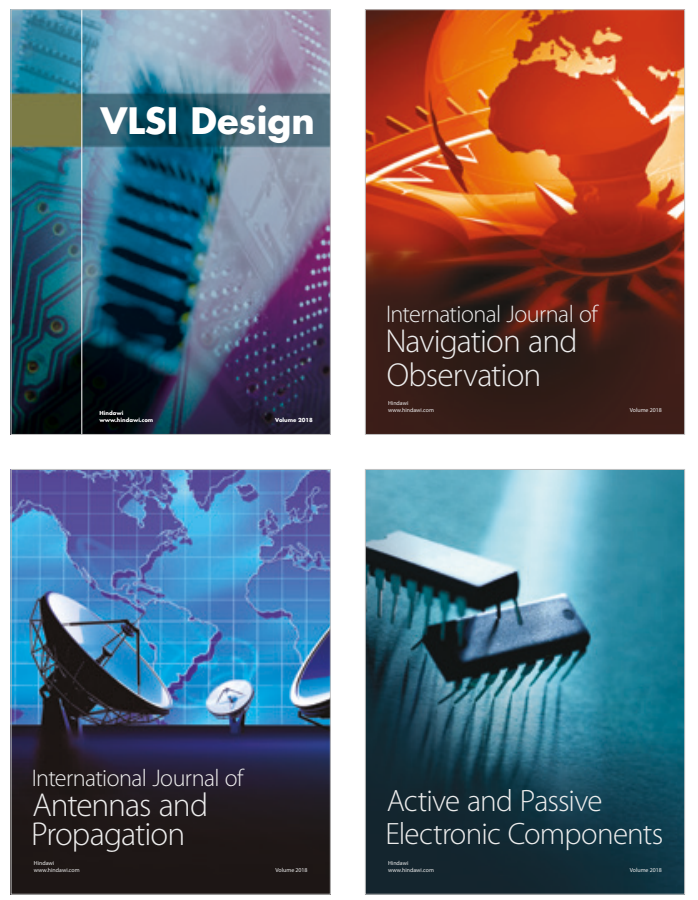
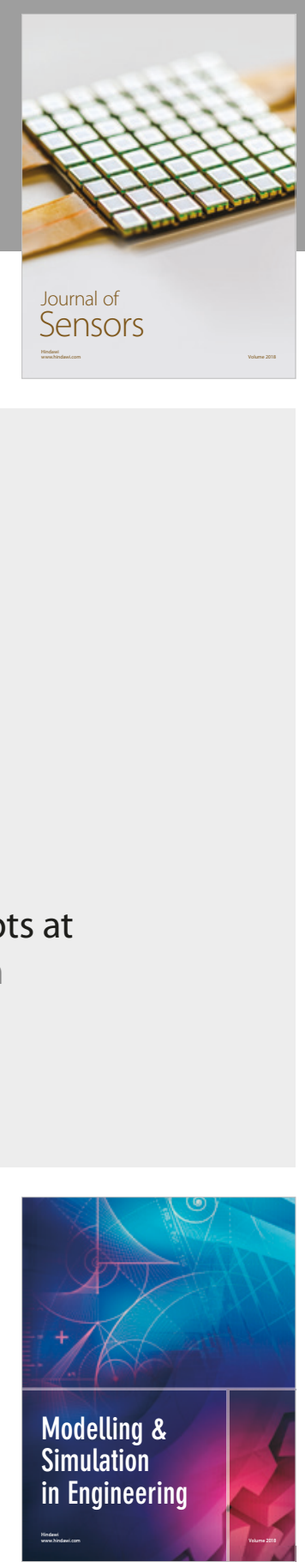

\section{Advances \\ Multimedia}
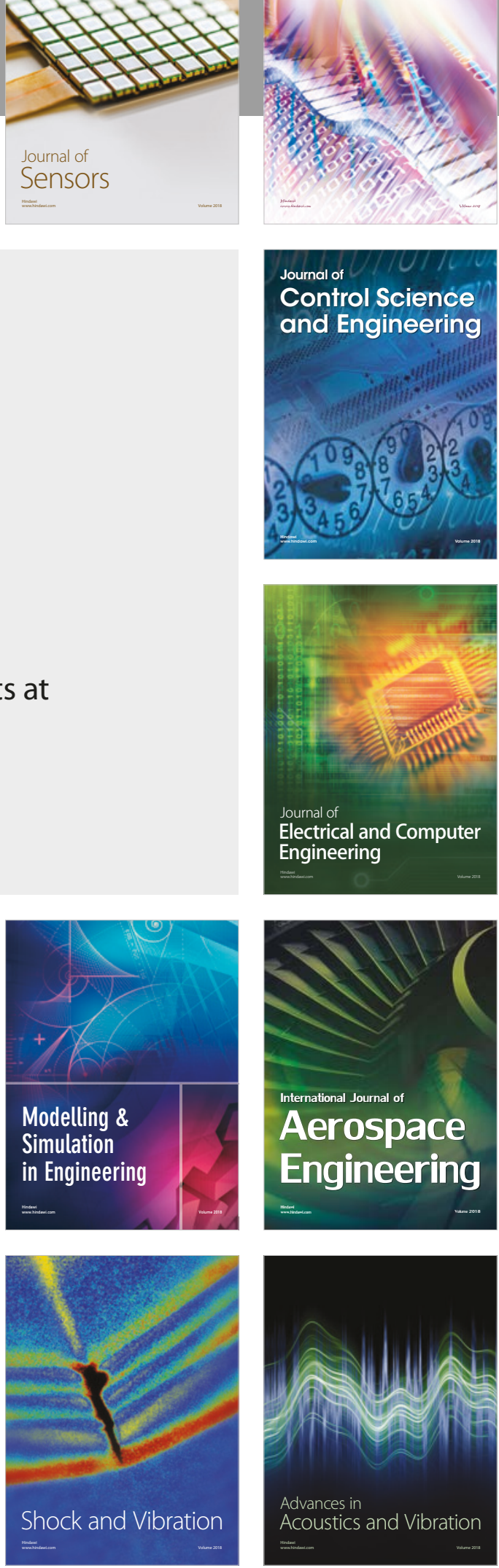